\title{
Community mothers' programme: extension to the travelling community in Ireland
}

\author{
P Fitzpatrick, B Molloy, Z Johnson
}

\begin{abstract}
Study objective-To see whether the community mothers' programme, using lay volunteer mothers to deliver a childhood development programme, could be extended successfully to the travelling community in Ireland.

Design - This was a prospective study of the travelling community; comparisons were made with results of a previous randomised trial of settled mothers.

Setting - A regional health authority in Ireland.

Participants - These comprised 39 traveller and 127 settled intervention mother/ infant pairs (randomised controlled trial (RCT) intervention); settled community mothers; 105 settled control pairs (RCT control). All mothers received standard support; traveller and RCT intervention groups also received the services of a community mother.
\end{abstract}

Main results - The travellers' sociodemographic profile differed significantly from the other groups. At the end of the study, traveller and intervention children were exposed to more cognitive games and nursery rhymes. There were significant differences in the proportions who received all three shots of their primary immunisation schedule before 12 months of age and who received "three in one" vaccination, with traveller children doing least well. The diet of traveller children surpassed that of RCT controls in all food groups except fruit; they were less likely to begin cows' milk before 26 weeks of age. Traveller mothers' diet was superior to that of RCT control and similar to RCT intervention mothers. Traveller and RCT intervention mothers were less likely to feel tired, feel miserable, and want to stay indoors than RCT control mothers.

Conclusions - The results of the community mothers' programme in the travelling community are encouraging; poor immunisation uptake remains a challenge.

(F Epidemiol Community Health 1997;51:299-303)

Health Information Unit, Eastern Health Board, Dr Steeven's Hospital, Dublin 8, Ireland

P Fitzpatrick

B Molloy

Z Johnson

Correspondence to: Dr P Fitzpatrick.

Accepted for publication September 1996 couraged to solve their own problems in child rearing. This programme was adopted in Ireland by public health nurses with encouraging results, ${ }^{2}$ however lack of resources meant that the programme in this format could not continue. It was therefore decided to recruit nonprofessionals in the form of successful experienced mothers to implement the programme, guided by family development nurses. Accordingly, a pilot project was launched in Dublin in 1983. In 1988 the project was extended and became known as the "community mothers' programme".

Potential community mothers are identified by local public health nurses and then interviewed by the family development nurse to assess suitability. Once accepted, the community mother undergoes a pre-service training course. Each community mother works under the guidance of a family development nurse who serves as a resource person, confidante, and monitor, working in partnership with 15-20 community mothers. Each community mother aims at supporting 5-15 parents.

A randomised controlled trial was conducted to examine whether lay volunteer community mothers could deliver a child development programme to disadvantaged first time mothers for children aged up to 1 year. ${ }^{3}$ Community mothers were shown to be able to deliver such a programme effectively.

In the light of these findings it was decided to extend the community mothers' programme to the travelling community. Experienced community mothers volunteered to visit the travelling mothers. They were given additional training to heighten their awareness of and sensitivity to the needs of the traveller parents.

Travelling people are a minority in Ireland, numbering 15888 in the 1986 census. ${ }^{4}$ They are recognised as a distinct group by virtue of their habitual travelling and their distinctive lifestyle. ${ }^{5}$ The travelling community has been defined as "an identifiable people, identified by themselves and by other members of the community, as people with their own distinctive lifestyle, traditionally of a nomadic nature but not now habitual wanderers". ${ }^{5}$ The ethnic origins are unclear and theories include the following: that they are a hybrid of Romany and Irish, and that they are descendants of those who chose to live beyond the ancient Irish Brehon Laws, of the dispossessed Irish clan chieftains, or of displaced peasants. ${ }^{6}$ Traditionally the travellers earned a living by the trade of tin-smithing, and a former word for traveller was tinker; this skill is now redundant due to technological change. Begging and intermarrying are common practices among the 
travelling community, both of which separate them from the rest of the community. ${ }^{7}$ The travelling people have a language of their own, called Shelta, or Gammon, which has been described more as a specialised vocabulary than a true language; its purpose is to enable travellers to speak to each other in the presence of "buffers", the traveller term for non-travellers. While many travellers are now housed or use official serviced caravan sites, a considerable number persistently live in unofficial sites, on unused waste ground or on the roadside. ${ }^{8}$

\section{Methods}

All travelling mothers delivering within Dublin or entering the region within four months of delivery over an 18 month period were offered the help and support of a community mother by the family development nurse. The traveller group was compared with the earlier intervention (randomised controlled trial (RCT) intervention) and control (RCT control) groups within the settled community. ${ }^{3}$ In the earlier evaluation, mothers had been randomly assigned to the RCT intervention group ( $n=$ 127), who received the support of a community mother, or to act as a RCT control $(n=105)$. All three groups received the standard support from their own local public health nurse, consisting of visits at birth, six weeks, and other times as required. All groups received invitations to attend for primary immunisations and for a developmental assessment at nine months.

Baseline demographic data were collected at the first interview. An evaluation questionnaire was administered on completion of the programme. All data were collected by the family development nurse.

\section{QUESTIONNAIRE}

Data were collected on demography, environmental factors, indicators of maternal wellbeing, immunisations, admissions to hospital, accidents, child and mother's nutrition, and developmental stimulation factors. $\mathrm{Nu}$ trition was assessed in part by dietary 24 hour recall. Responses were categorised as appropriate or inappropriate on advice from nutritionists-inappropriate referring to either too little or too much of a particular food.

Developmental stimulation was assessed in several ways: mothers were asked how often they showed pictures to their child; how often they sang or said nursery rhymes; and what type of games they played with them. Games were divided into "cognitive" and "motor". Cognitive games included hide and seek, singing, and number games, while motor games included playing with a ball and floor games. Each game mentioned was given a score of one, and totals were calculated for each type. The frequency with which mothers sang nursery rhymes was scored on a $10 \mathrm{~cm}$ analogue scale which had been used in evaluating the child development programme. ${ }^{2}$

\section{STATISTICAL METHODS}

Statistical analysis was done by using the $S A S$ system, version 6.09 (SAS Institute, Cary, North Carolina). The $\chi^{2}$ test was used for comparisons of proportions. For two group analysis of continuous variables, the Wilcoxon rank sum test was used. For multiple group analysis of continuous variables analysis of variance with Bonferroni $t$ tests for comparison of means were used; where assumptions for analysis of variance could not be met the Kruskall-Wallis test was used.

\section{Results}

Thirty nine traveller mother and infant pairs participated in the programme. Their data are reviewed in the light of the results of our previous study. ${ }^{3}$

Traveller children were significantly older (mean 17.6; range 8-32 months) on completion of the programme than the RCT intervention (mean 12.2 months) and RCT control groups (mean 11.9 months), where the oldest child at the time of interviewing was 16 months $(p<0.001)$. Traveller mothers received significantly fewer visits from the community mother (mean 8.9) during the course of the programme than the RCT intervention mothers (mean $9.5 ; \mathrm{p}<0.05) ; 11(28.2 \%)$ received at least 10 visits compared with $82(64.6 \%)$ of the RCT intervention group ( $p<0.001)$. While all mothers in the original study were first time parents, some traveller mothers in the programme had more than one child.

\section{SOCIODEMOGRAPHIC/ENVIRONMENTAL CHARACTERISTICS}

The sociodemographic characteristics of the three groups are shown in table 1. Traveller

Table 1 Sociodemographic profile of the three study groups. Unless stated otherwise figures are number (\%) of subjects

\begin{tabular}{|c|c|c|c|c|c|}
\hline Variable & Category & $\begin{array}{l}\text { Traveller } \\
\text { group }\end{array}$ & $\begin{array}{l}\text { RCT intervention } \\
\text { group }\end{array}$ & $\begin{array}{l}\text { RCT control } \\
\text { group }\end{array}$ & $p$ value \\
\hline Sex of infant & $\begin{array}{l}\text { Male } \\
\text { Female }\end{array}$ & $\begin{array}{l}22(56.4) \\
17(43.6)\end{array}$ & $\begin{array}{l}62(48.8) \\
65(51.2)\end{array}$ & $\begin{array}{l}51(48.6) \\
54(51.4)\end{array}$ & NS \\
\hline Mothers' age (y) & Mean (SD) & $25(5.0)$ & $24.1(4.4)$ & $23.1(3.7)$ & 0.008 \\
\hline Mothers' age at school-leaving (y) & Mean (SD) & $12.9(2.6)$ & $15.9(1.4)$ & $15.7(1.7)$ & 0.0001 \\
\hline Mothers' marital status & Single & $\begin{array}{r}5(12.8) \\
34(87.2)\end{array}$ & $\begin{array}{l}65(51.2) \\
61(48.0)\end{array}$ & $\begin{array}{l}64(60.9) \\
40(38.1)\end{array}$ & 0.0001 \\
\hline Mothers' employment status & Employed & $5(12.8)$ & $37(29.0)$ & $\begin{array}{l}18(17.1) \\
87(82.9)\end{array}$ & 0.029 \\
\hline Social class & $\begin{array}{l}\text { I, II, III } \\
\text { IV, V, VI } \\
\text { Unknown }\end{array}$ & $\begin{array}{c}34(0.0) \\
0(100) \\
39(100.0) \\
0(0.0)\end{array}$ & $\begin{array}{r}16(12.6) \\
110(86.6) \\
1(0.8)\end{array}$ & $\begin{array}{c}8(7.6) \\
93(88.6) \\
4(3.8)\end{array}$ & NS \\
\hline
\end{tabular}


Table 2 Indicators of maternal wellbeing on completion of the programme. Results expressed as numbers (\%) of subjects

\begin{tabular}{|c|c|c|c|c|}
\hline Variable & Group & Yes & No & $p$ value \\
\hline Tired & $\begin{array}{l}\text { Traveller }(n=39) \\
\text { RCT intervention }(n=127) \\
\text { RCT control }(n=105)\end{array}$ & $\begin{array}{l}33(84.6) \\
99(78.0) \\
95(90.5)\end{array}$ & $\begin{array}{l}6(15.4) \\
28(22.0) \\
10(9.5)\end{array}$ & 0.036 \\
\hline Headaches & $\begin{array}{l}\text { Traveller }(n=39) \\
\text { RCT intervention }(n=127) \\
\text { RCT control }(n=105)\end{array}$ & $\begin{array}{l}19(48.7) \\
62(48.8) \\
52(49.5)\end{array}$ & $\begin{array}{l}20(51.3) \\
65(51.2) \\
53(50.5)\end{array}$ & NS \\
\hline Miserable & $\begin{array}{l}\text { Traveller }(n=39) \\
\text { RCT intervention }(n=127) \\
\text { RCT control }(n=105)\end{array}$ & $\begin{array}{l}23(59.0) \\
73(57.5) \\
80(76.2)\end{array}$ & $\begin{array}{l}16(41.0) \\
54(42.5) \\
25(23.8)\end{array}$ & 0.008 \\
\hline Wanting to stay in & $\begin{array}{l}\text { Traveller }(n=39) \\
\text { RCT intervention }(n=127) \\
\text { RCT control }(n=105)\end{array}$ & $\begin{array}{l}18(46.2) \\
40(31.5) \\
57(54.3)\end{array}$ & $\begin{array}{l}21(53.8) \\
87(68.5) \\
48(45.7)\end{array}$ & 0.002 \\
\hline
\end{tabular}

$\mathrm{RCT}=$ randomised controlled trial. children aged $\geq 15$ months at the end of the programme, $36 \%$ had received MMR (mumps, measles, and rubella) immunisation.

\section{ACCIDENTS AND HOSPITALISATION}

Sixty nine children in total were admitted to hospital during the programme: 24 (61.5\%) from the traveller group, 24 (19\%) from the RCT intervention group, and $21(20 \%)$ RCT controls $(p<0.001)$ (table 3$)$. There was a significant difference between the three groups in the mean number of days spent in hospital $(p<0.001$ ); traveller children (mean 6.1 days) spent significantly longer than both the RCT intervention children (mean 2.6 days; $p<0.05$, Bonferroni) and RCT control children (mean 1.3 days; $\mathrm{p}<0.05$, Bonferroni), while the latter two groups did not differ significantly from each other. Of those admitted to a hospital, the mean length of stay was significantly longer in the RCT intervention group (14.0 days) than in the RCT control group ( 7.0 days; $\mathrm{p}<0.05$, Bonferroni); the traveller group (mean 10.8 days) did not differ significantly from either of the other groups. Fifteen children had an accident requiring a visit to a hospital during the periods of study, four in the traveller group, three in the RCT intervention group, and eight among RCT controls (NS). All the accidents among travellers were falls; in the other groups seven accidents were falls, two children were burnt, one pulled a fireguard on himself and another took an adult's medicine. communal toilet and jur private toilet inside their home. Just under one third of travellers $(12 ; 30.8 \%)$ had no electricity, $36(92.3 \%)$ had no smoke alarm, and $33(84.6 \%)$ had no garden.

\section{INDICATORS OF MATERNAL WELLBEING}

Table 2 outlines the differences in the three groups as regards mothers' sense of wellbeing at the end of the programme. Apart from headaches, in which all groups were similar, traveller and RCT intervention mothers scored significantly better in all indicators of wellbeing than RCT control mothers.

\section{IMMUNISATION}

One hundred and ninety seven children had received all three shots of their primary immunisation schedule by their 1 st birthday with a significant difference between the proportions in each group: $22 / 39$ traveller children $(56.4 \%)$, $67 / 105$ RCT control children (63.8\%), 108/ 127 RCT intervention children (85.0\%) $(p<0.001)$. Of those who received at least one primary immunisation, there was a significant difference in the proportions in each group receiving diphtheria-tetanus-pertussis vaccine: 19/34 traveller children $(55.9 \%), 72 / 99$ RCT control children $(72.7 \%), 99 / 125$ RCT intervention children $(79.2 \%)(p<0.05)$.

Forty three per cent of traveller children had received one or more HIB immunisations. Of those 34 traveller children who had at least one primary immunisation $50 \%$ had received at least one HIB immunisation. Of the 25 traveller

\section{NUTRITION}

The results of the 24 hour dietary recall are shown for children and their mothers in tables 4 and 5. Dietary protein intakes could not be directly compared as total protein intake was assessed in the traveller group, while in the previous study ${ }^{3}$ separate data were collected on animal and non-animal protein; $84.6 \%$ of traveller children and $84.6 \%$ of their mothers consumed appropriate amounts of protein. Except for fruit consumption, traveller children performed better than RCT controls for all other food groups and energy intakes. They were on a par with the RCT intervention group

Table 3 Number of admissions to hospital

\begin{tabular}{lccc}
\hline Condition & $\begin{array}{l}\text { Traveller } \\
\text { group } \\
(n=39)\end{array}$ & $\begin{array}{l}R C T \text { intervention } \\
\text { group } \\
(n=127)\end{array}$ & $\begin{array}{l}\text { RCT control } \\
\text { group } \\
(n=105)^{*}\end{array}$ \\
\hline Chest infection & 8 & 7 & 5 \\
Gastroenteritis & 7 & 5 & 4 \\
Tonsillitis & 0 & 2 & 2 \\
Meningitis & 1 & 1 & 0 \\
Pertussis & 0 & 0 & 1 \\
Other infections & 5 & 4 & 5 \\
Feeding problems & 0 & 2 & 2 \\
Prematurity & 0 & 1 & 0 \\
Near miss cot death & 0 & 1 & 0 \\
Hernia repair & 0 & 1 & 0 \\
Epilepsy & 1 & 0 & 0 \\
Rectal bleeding & 1 & 0 & 0 \\
Measles & 3 & 0 & 0 \\
Scalds & 0 & 0 & 1 \\
Tablet ingestion & 0 & 0 & 1 \\
Sprained arm & 1 & 0 & 0 \\
Total & $* 27$ & 24 & 21 \\
\hline
\end{tabular}

* Three children admitted twice. $\mathrm{RCT}=$ randomised controlled trial. 
Table 4 Twenty four hour dietary recall history for children at evaluation. Results expressed as numbers (\%) of subjects

\begin{tabular}{llcrr}
\hline Food item & Group & Inappropriate & Appropriate & p value \\
\hline Wholefoods & Traveller $(\mathrm{n}=39)$ & $16(41.0)$ & $23(59.0)$ & 0.0001 \\
& RCT intervention $(\mathrm{n}=127)$ & $18(14.2)$ & $109(85.8)$ & \\
Vegetables & RCT control $(\mathrm{n}=105)$ & $57(54.3)$ & $48(45.7)$ & \\
& Traveller $(\mathrm{n}=39)$ & $12(30.8)$ & $27(69.2)$ & 0.0001 \\
& RCT intervention $(\mathrm{n}=127)$ & $15(11.8)$ & $112(88.2)$ & \\
Fruit & RCT control $(\mathrm{n}=105)$ & $40(38.1)$ & $65(61.9)$ & \\
& Traveller $(\mathrm{n}=39)$ & $25(64.1)$ & $14(35.9)$ & 0.0001 \\
& RCT intervention $(\mathrm{n}=127)$ & $29(22.8)$ & $98(77.2)$ & \\
Milk & RCT control $(\mathrm{n}=105)$ & $64(60.9)$ & $41(39.1)$ & \\
& Traveller $(\mathrm{n}=39)$ & $4(10.3)$ & $35(89.7)$ & 0.0001 \\
& RCT intervention $(\mathrm{n}=127)$ & $8(6.3)$ & $119(93.7)$ & \\
Energy intake & RCT control $(\mathrm{n}=105)$ & $29(27.6)$ & $76(72.4)$ & \\
& Traveller $(\mathrm{n}=39)$ & $3(7.7)$ & $36(92.3)$ & 0.0001 \\
& RCT intervention $(\mathrm{n}=127)$ & $9(7.1)$ & $118(92.9)$ & \\
& RCT control $(\mathbf{n}=105)$ & $46(43.8)$ & $59(56.2)$ & \\
\hline
\end{tabular}

$\mathbf{R C T}=$ randomised controlled trial.

Table 5 Twenty four hour dietary recall history for mothers at evaluation. Results expressed as numbers (\%) of subjects

\begin{tabular}{lllll}
\hline Food item & Group & Inappropriate & Appropriate & p value \\
\hline Wholefoods & Traveller $(\mathrm{n}=39)$ & $20(51.3)$ & $19(48.7)$ & 0.0001 \\
& RCT intervention $(\mathrm{n}=127)$ & $43(33.9)$ & $84(66.1)$ & \\
Vegetables & RCT control $(\mathrm{n}=105)$ & $81(77.1)$ & $24(22.9)$ & \\
& Traveller $(\mathrm{n}=39)$ & $12(30.8)$ & $27(69.2)$ & 0.0001 \\
& RCT intervention $(\mathrm{n}=127)$ & $46(36.2)$ & $81(63.8)$ & \\
Fruit & RCT control $(\mathrm{n}=105)$ & $62(59.0)$ & $43(41.0)$ & \\
& Traveller $(\mathrm{n}=39)$ & $27(69.2)$ & $12(30.8)$ & 0.025 \\
& RCT intervention $(\mathrm{n}=127)$ & $72(56.7)$ & $55(43.3)$ & \\
Milk & RCT control $(\mathrm{n}=105)$ & $77(73.3)$ & $28(26.7)$ & \\
& Traveller $(\mathrm{n}=39)$ & $19(48.7)$ & $20(51.3)$ & 0.001 \\
& RCT intentrention $(\mathrm{n}=127)$ & $56(44.1)$ & $71(55.9)$ & \\
Energy intake & RCT control $(\mathrm{n}=105)$ & $72(68.6)$ & $33(31.4)$ & \\
& Traveller $(\mathrm{n}=39)$ & $4(10.3)$ & $35(89.7)$ & 0.0001 \\
& RCT intervention $(\mathrm{n}=127)$ & $33(26.0)$ & $94(74.0)$ & \\
& RCT control $(\mathrm{n}=105)$ & $52(49.1)$ & $53(50.9)$ & \\
\hline
\end{tabular}

$\mathrm{RCT}=$ randomised controlled trial.

Table 6 Developmental scores in children from the three study groups

\begin{tabular}{llll}
\hline Variable & Group & Mean $(S D)$ & p value \\
\hline Cognitive games & Traveller $(\mathrm{n}=39)$ & $2.40(1.74)$ & 0.0001 \\
& RCT intervention $(\mathrm{n}=127)$ & $3.75(2.11)$ & \\
Motor games & RCT control $(\mathrm{n}=105)$ & $1.62(1.39)$ & \multirow{2}{*}{ NS } \\
& Traveller $(\mathrm{n}=39)$ & $1.10(1.02)$ & \\
Nursery rhymes & RCT intervention $(\mathrm{n}=127)$ & $0.83(0.76)$ & \\
& RCT control $(\mathrm{n}=105)$ & $0.76(0.84)$ & \multirow{2}{*}{0.0001} \\
& Traveller $(\mathrm{n}=39)$ & $6.39(3.16)$ & \\
& RCT intervention $(\mathrm{n}=127)$ & $7.74(1.65)$ & \\
& RCT control $(\mathrm{n}=105)$ & $3.50(3.24)$ & \\
\hline
\end{tabular}

$\mathrm{RCT}=$ randomised control trial.

\section{PERCEIVED MATERNAL BENEFIT}

Ninety five per cent of traveller mothers felt that they had derived benefit from the community mothers' programme. While most felt they had learnt from the programme $(76.9 \%)$, others cited friendship (15.4\%) and interest in reading and writing $(2.6 \%)$ as the main beneficial aspects.

\section{Discussion}

The travelling community presents a challenge to health promotion and preventive medicine. The perinatal and infant mortality rates of travellers in 1987 were $28.3 / 1000$ and $18.1 /$ $1000,{ }^{9}$ respectively, compared with the national figures in 1987 of $10.4 / 1000$ and $7.9 / 1000 .^{10}$ There is poor uptake of antenatal and postnatal services. ${ }^{8}$ There is a reluctance among many general practitioners to take travellers onto their patient lists and a lack of established relationships with general practitioners. ${ }^{8}$ The standardised mortality ratio (SMR) of unhoused travellers for accidents is 843 and for housed travellers is 135, against an Irish SMR of $100 .^{9}$

The child development programme from which the community mothers' programme evolved is a well designed intervention programme whose essential feature is empowerment of the parent. New mothers are seen as equals with the community mother, who, rather than handing down advice, shares her own parenting experiences and raises the mothers' self esteem and self confidence as a parent. By using non-professionals to deliver the programme, the community mothers' programme differs from traditional methods of health promotion.

Although a travellers control group would be desirable, randomisation in a tight-knit community would have been very difficult. Only $50-60 \%$ of traveller children are located by the public health nursing service at the child's 1 st birthday, owing to the high mobility of the traveller community. ${ }^{11}$ The traveller community overall is sensitive to intrusion and reluctant to give personal information. In addition resources for evaluation were limited and the value of tracking a very mobile group without offering them any benefit was dubious, as it was felt that the response rate would be very poor in any traveller control group.

Some would suggest that the settled population would be expected to be better than the travelling population at baseline in many aspects evaluated. Interim findings of a study into travellers' health provide evidence of a low uptake of infant health services by the travelling community, in particular immunisation uptake overall and attendance at developmental screening, both of which are much less than $50 \% .^{11}$ There is low uptake of specialist child health services. A low rate of public health nursing intervention is found, with most visits taking place at home as opposed to at clinics. ${ }^{12}$ There is poor continuity of care.$^{812}$ In many parts of the country there is no formal health education for travellers. ${ }^{8}$ Lack of regular school attendance and adult illiteracy are problems. ${ }^{8}$ 
Thus the use of settled controls in this study allows us demonstrate even more sharply the benefit of this programme, since the travelling community exposed to the community mothers' programme surpassed the controls in almost all indicators assessed.

The family development nurses collected all data in this study. While ideally independent evaluators should be used, because travellers are a marginalised group which is suspicious of strangers and officialdom it was felt that it would be difficult to achieve a reasonable response with evaluators who were not well known to the travellers. Family development nurses also collected data in the original study, ${ }^{3}$ so any bias would be in the same direction in both studies and therefore comparison remains acceptable.

Direct comparisons were not deemed appropriate in every instance. Because of problems of illiteracy, information was sought from traveller mothers about the frequency with which they showed their children pictures, whereas the settled community mothers had been asked about reading to their children. However, reading to very young children normally involves use of picture books and thus the type of stimulation is likely to be similar for both communities.

Traveller children were older on starting and on completion of the programme than their settled counterparts. The reason for this was the mobility of the travelling community. Traveller children were accepted onto the programme if they arrived into the area within a few months of their birth. Sometimes traveller families moved away at the end of the programme for a while before returning, at which time the interview was completed. Some families moved away in the middle of the programme, then returned and the programme continued. The results should be interpreted in light of the fact that traveller children were older and were not always the firstborn. The older age of the traveller children at the time of interview may account in part for the difference in proportions of children in each group who were hospitalised during the programme. Children were admitted for various conditions that were not addressed by the community mothers' programme and could not have been expected to be influenced by it.

Given the disadvantageous starting point of the travelling community the results of the programme for this group are encouraging, especially regarding dietary habits, indicators of maternal wellbeing, and developmental stimulation of children. It is held that preventive programmes will have a low priority among travellers as long as more immediate needs such as shelter and warmth are unmet ${ }^{13}$; yet $95 \%$ of traveller mothers looked favourably on the programme.

Additional benefits may derive from the introduction of the community mothers' programme. Minimal contact between settled and travelling communities contributes to barriers of prejudice based on fear and ignorance on both sides. ${ }^{8}$ In addition, it often contributes to the creation of phobias, intolerance, misconceptions, hostility, and aggression. The contact by settled community mothers and family development nurses was well received by most travellers and the programme may go some way towards improving the relationship between the settled and travelling communities. Illiteracy is still a major barrier in allowing adult travellers to participate fully in society. ${ }^{8}$ Poor school attendance among traveller children is a persistent concern. ${ }^{8}$ Interest in reading and writing generated through the programme may serve as an incentive to traveller mothers to seek education for their children and themselves.

The low uptake of vaccinations among the travellers, despite the community mothers' programme, may point to deep rooted cultural fears. The high hospitalisation rate emphasises the potential scope for opportunistic vaccination of this group at outpatient visits, casualty visits, and, if appropriate, when inpatients in a hospital. Special initiatives have been introduced by individual health boards to attempt to redress some of the difficulties with the delivery of health services to the traveller community. Specialist outreach clinics have been introduced in some parts of the country, using either a mobile or on-site clinic. Specialist public health nurses have also been introduced. Halting site inspections are now carried out in each health board, to ensure a standard level of service provision and safety.

We thank the following for their assistance and cooperation with this study: the parents and children whose experiences form the basis of this report; the family development nurses who completed the fieldwork, B Rooney, T Keegan, A Savage, $B$ Cawley, and $M$ Davey Borresen; the community mothers who visited the travellers, $C$ Arnold, $C$ O'Toole, $S$ Mullen, $O$ Dunne, $H$ Kennedy, and $P$ Fitzgerald; the Eastern Health Board, Dublin.

1 Barker W. The child development programme: a collaborative programme linking parents, community and health visitors. Bristol: Early Childhood Development Unit, University Bristol: Early Chil

2 Barker W, Anderson R. The child development programme: an evaluation of process and outcome. Bristol: Early Childhood Development Unit, University of Bristol, 1984.

3 Johnson Z, Howell F, Molloy B. Community mothers' programme: randomised controlled trial of non-professional intervention in parenting. BMF 1993;306:144952.

4 Barry J, Daly L. The travellers' health status study; census of travelling people, 1986. Dublin: Health Research Board, 1988.

5 The Travelling People Review Body. Report of the travelling people review body. Dublin: Stationery Office, 1983.

6 Kiely J. The utilisation of antenatal care and the outcome of pregnancy in a population of travellers. Dublin: Faculty of pregnancy in a population of travellers. Dublin: Faculty of

7 Gmelch S. Tinkers and travellers-Ireland's nomads. Dublin: O'Brien Press, 1975

8 Task force on the travelling community. Report of the task force on the travelling community. Dublin: Stationery Office, 1995.

9 Barry J, Herity B, Solan J. The travellers' health status study. Vital statistics of travelling people, 1987. Dublin: Health Research Board, 1989.

10 Department of Health. Report on vital statistics 1987. Dublin: Stationery Office, 1990

11 Task force on the travelling community. Interim progress report of the task force on the travelling community. Dublin: Department of Equality and Law Reform, 1994.

12 O'Donovan O, McKenna V, Kelleher C, McCarthy P. Health service provision for the travelling community in Ireland. Report service provision for the travelling community in Ireland. Report
of the task force on the travelling community research papers of the task force on the travelling community research papers
document No 12. Dublin: Department of Equality and Law Reform, 1995.

13 Barry J. Health care of Irish travellers. Irish Doctor 1991;4: 